\section{Dr. Owada, et al, reply}

\section{To the Editor:}

We thank Dr. Pipitone, et al for their interest ${ }^{1}$ in our article ${ }^{2}$. Pipitone, et al reported high sensitivity of active myositis by ${ }^{18} \mathrm{~F}$ fluorodeoxyglucose positron emission tomography (FDG-PET) imaging ${ }^{3}$ compared with that in our study, when they defined active myositis based on the ratio of standardized uptake values of proximal muscles to that of the liver. Moreover, they reported that the PET sensitivity was decreased to a value similar to ours when they used the definition of active myositis in our study, a method comparing the uptake of muscle to the liver qualitatively, not quantitatively.

These findings indicate the importance of methods defining activity of myositis and we agree that a method for grading proposed by Walter, et $a l^{4}$ might be too strict to define activity of myositis.

It is to be clarified what methods and definitions are suitable for management of myositis in clinical practice. Moreover, the clinical significance of PET examination in measuring disease activity of myositis remains to be determined. Is PET imaging, an expensive and radiation-exposing examination, superior to other methods measuring disease activity including serum creatine kinase (CK) levels and magnetic resonance imaging examinations? Can PET provide information on myositis that could not be obtained by other methods, although PET is a good tool for detecting hidden malignancies?

It is also important to clarify what conditions the PET imaging reflects: cell infiltration, muscle cell response to injury, or regeneration of muscles. Pipitone, et al reported no correlation of FDG muscle uptake with disease duration, CK levels, muscle strength, or magnetic resonance scores ${ }^{3}$. We showed only a tendency in patients with the FDG uptake to have myositis with endomysial cell infiltration ${ }^{2}$. In addition, cell infiltration into distal muscles as well as proximal ones had been reported ${ }^{5}$; significant FDG uptake in the distal muscles was not observed in our study.
To answer these questions, further research (e.g., a longitudinal study and a study including patients with noninflammatory myopathy such as muscle dystrophy as controls) is required.

TAKAYOSHI OWADA, MD, PhD; REIKA MAEZAWA, MD; KAZUHIRO KURASAWA, MD, PhD, Clinical Immunology, Dokkyo Medical University, Mibu, Tochigi, Japan. Address correspondence to Dr. K. Kurasawa, 880 Kita-Kobayashi, Mibu, Tochigi 321-0293, Japan. E-mail: kurasawa@dokkyomed.ac.jp

\section{REFERENCES}

1. Pipitone N, Versari A, Salvarani C. Is F-18 Fluorodeoxyglucose positron emission tomography useful to assess activity of myositis? [letter]. J Rheumatol 2013;40:91.

2. Owada T, Maezawa R, Kurasawa K, Okada H, Arai S, Fukuda T. Detection of inflammatory lesions by F-18 fluorodeoxyglucose positron emission tomography in patients with polymyositis and dermatomyositis. J Rheumatol 2012;39:1659-65.

3. Pipitone N, Versari A, Zuccoli G, Levrini G, Macchioni P, Bajocchi $\mathrm{G}$, et al. 18F-Fluorodeoxyglucose positron emission tomography for the assessment of myositis: A case series. Clin Exp Rheumatol 2012;30:570-3.

4. Walter MA, Melzer RA, Schindler C, Muller-Brand J, Tyndall A, Nitzsche EU. The value of [18F]FDG-PET in the diagnosis of large-vessel vasculitis and the assessment of activity and extent of disease. Eur J Nucl Med Mol Imaging 2005;32:674-81.

5. Dorph C, Englund P, Nennesmo I, Lundberg IE. Signs of inflammation in both symptomatic and asymptomatic muscles from patients with polymyositis and dermatomyositis. Ann Rheum Dis 2006;65:1565-71.

J Rheumatol 2013;40:1; doi:10.3899/jrheum.121243 